\title{
Durability Control of Brickwork's Material Including Operation Parameters of the Building Enclosure
}

\author{
Dmitry Zheldakov ${ }^{*}$, Radik Mustafin ${ }^{2}$, Vladimir Kozlov ${ }^{1}$, Askar Gaysin ${ }^{3}$, Dmitriy Sinitsin ${ }^{4}$, Bulat Bulatov ${ }^{2}$ \\ ${ }^{1}$ Laboratory of Construction Thermophysics, Research Institute of Building Physics, Russian Academy of Architecture and \\ Building Science, Lokomotivny Passage, 21, Moscow 127238, Russian Federation \\ ${ }^{2}$ Department of Environmental Management, Construction and Hydraulics, Federal State Budgetary Educational Establishment \\ of Higher Education "Bashkir State Agrarian University", 50-letia Octyabrya Str., 34, Ufa 450057, Russian Federation \\ ${ }^{3}$ Department of Building Structures, Federal State Budgetary Educational Establishment of Higher Education "Ufa State \\ Petroleum Technological University", Rossiyskaya Str., 13, Ufa 450081, Russian Federation \\ ${ }^{4}$ Department of Building Structures, Federal State Budgetary Educational Establishment of Higher Education "Ufa State \\ Petroleum Technological University", Cosmonauts Str., 1, Ufa 450064, Russian Federation
}

Corresponding Author Email: dmzheldakov@rambler.ru

https://doi.org/10.18280/mmep.080605

Received: 4 June 2021

Accepted: 29 September 2021

\section{Keywords:}

brickwork, chemical corrosion, durability, mathematical model, reaction speed

\begin{abstract}
This paper aims to develop a method to determine material durability based on physicochemical laws that describe chemical corrosion in building enclosures. The subject of this research is studying the chemical corrosion in the material in building constructions. The object of this research is the material of building ceramics. Methods that the authors used for reaching this goal include developing a multi-staged process of material degradation of building ceramics, conduction of thermodynamic calculations, and conducting laboratory research on process kinetics. The results of kinetic researches are generalized based on a developed mathematical model. This comprehensive approach to solving the goal task allowed obtaining the following results: research methods of chemical processes in brick material and its plaster on humidification were developed. A mathematical model for evaluating material degradation in time with the changing climatic influence on enclosure was developed.
\end{abstract}

\section{INTRODUCTION}

Many foreign researchers dedicated their works to the evolution of modelling methods of corrosion effects for concrete $[1,2]$. The mathematical models that describe processes of material degradation in the construction are divided into empirical models, built on behavioral patterns of material under the environmental effects [3, 4] and phenomenological models based on a physicochemical laws of reaction processes of chemical corrosion in the material $[5,6]$. The advantage of physicochemical models compared to empirical models [7] is a description of process kinetics at a broader spectrum of environmental parameters and characteristics of a material. Based on an opinion $[8,9]$, the disadvantage of current physicochemical models is that developing in general cases considers the data about kinetics of corrosion processes obtained in the results of laboratory research on samples with a limited set of external factors [10]. This evaluation can be controversial. They probably studied in physicochemical models a limited set of external factors determined by the wrong approach for describing the whole degradation process. Exactly this leads to result errors of the whole physicochemical model at the last stage. Combining the results of laboratory studies described in the form of empirical models with a phenomenological model built based on the fundamental physical chemistry laws will create a correct model of the material durability. In this case, the correct integration of empirical models into the phenomenological model to be built is of key importance.

It should be noted that almost every developing mathematical model for evaluating material durability during its operation in construction's enclosure developed with an accounting either the effect of aggressive environment on a construction's material or with an accounting of mechanical effect on construction. Besides, some authors are trying to analyze the material durability in the construction considering both chemical, environmental, and mechanical effects $[11,12]$. These works consider general construction models as a set: the construction element models, material models, environmental effect models, models of reaching the critical state [13]. However, the processes under consideration influence each other. For example, the destruction of the material and external factors directly affects the time when the material or structure reaches the limit state. Such a dependence is very complex and makes using this model more complicated in the automatic control of destruction processes.

Moreover, none of the analyzed mathematical models reviews the material's inner chemical corrosion processes without any external effects. For example, material durability is evaluated by mechanical destruction under negative temperatures [14, 15].

Calculation of the durability of brick's material using the main parameter of brick's grade by frost-resistance $[16,17]$ is impossible because this parameter provides relative evaluation 
by criteria "yes/no" destruction of the material after a certain amount of freeze-thaw cycles.

Besides, the field research proved $[18,19]$ that the process of brick degradation can proceed with positive temperatures only. The use of the frost-resistance parameter for durability evaluation will lead to significant errors, even though some researchers have proposed many [20,21].

The approach to determining material's durability based on the amount of freeze-thaw cycles doesn't explain a significant amount of degradation processes, such as degradation in positive temperatures, spot destruction of discrete bricks, high-temperature degradation and others.

Based on field researches on brick destruction in brickworks, the following conclusions can be made: the amount of freezethaw cycles is not a deterministic parameter of the brick durability; degradation speed of the material of discrete bricks in the brickwork in the same climatic conditions (humidity, temperature cycles, including zero crossings) is different for each material. Notably, the mechanism of degradation of the brick's material in the brickwork is the same. It does not depend on the time of brickwork was made and the geographical location of the building with brick enclosures.

Zheldakov [18, 19, 22], in his work, suggested a hypothesis that the degradation process in brick's material can be described by the rules of physical chemistry assuming the chemical nature of degradation processes in the wall ceramic's material. This approach allows more precisely and more correctly describing the degradation process and determines the durability of the material in time units. Moreover, the polythermal effect on the brick material can lead to the acceleration of material destruction that is weakened by chemical corrosion. The research aims at proving the scientific hypothesis formulated above.

Chemical degradation of the brick and brickwork describes by the multi-staged process. In the first stage, alkalis are formed in the brick's material from the oxides of alkalis and earth-alkalis metals. Alkali can also come from a cement-sand mortar. In the leaching process, calcium hydroxide is mainly formed in the cement-sand mortar [23, 24]. In the second stage, the interaction between alkalis, formed in the brick material and/or came from cement-sand mortar, and silicon and aluminium oxides in the amorphous phase of brick material. Brick's material is wholly destructed to the particles of $10^{-5}$ to $10^{-6} \mathrm{~m}$ because the amorphous component is the critical phase of the material. The non-chemical stage in the degradation process is also crucial - the stage of the material humidification. The following research results on the process' kinetics prove that the stage of material humidification is the limiting stage for the whole degradation process.

Thermodynamical calculations were made for the theoretical substantiation of this hypothesis and the clarification of chemical reactions that mainly occur in the chemical degradation of the wall ceramic's material. Two hundred sixty-five chemical reactions were accounted for in the calculations that possibly take part in the process. Calculations were made with the use of standard thermodynamical characteristics of the agents with the calculation of Gibbs function of the reaction of the temperature. Based on those calculations, the direction of reactions and evaluation of their energetic possibility was determined, and a probability of the reaction in one system with the condition of identical initial structural and kinetic factors and determined the stability of the formed links. Thermodynamical calculations: theoretically proven the correctness of the suggested scheme of the degradation process of wall's ceramics; allowed to clarify the degradation processes with the determination of the final product of the reaction; allowed to formulate the main directions of the researches of the process' kinetics. These directions determined based on the main factors that affect the speed of chemical reactions: concentration of the agents involved in the reaction, temperatures of the process and, since the agents in different phases take part in the reaction (which are fluid (alkali) and solid agent (alumosilicates)) - surface areas of the reagents.

\section{MATERIALS AND METHODS}

\subsection{Research design}

Two methods have been developed to study the kinetics of the process. The first method is studying the reaction rate during the formation of the alkali in the brick material (determination of the moisture corrosiveness). This method allows obtaining numerical values of the rate of formation of alkali during the interaction of oxides of alkaline and earth metals present in the brick material when it is moistened. The second method determines the rate of destruction of the brick material under the action of alkalis. This method allows using a new performance indicator of the structural ceramics, the chemical destruction coefficient $\mathrm{Cd}$. The introduced indicator has a dimension of $[\% /$ hour $]$, which allows its use for calculating the material durability.

Thus, applying the two methods allows obtaining the kinetic characteristics of the two chemical stages of the structural ceramics destruction: the alkali concentration in the brick material when it is moistened and the destruction rate under the action of alkalis a specific concentration at a certain temperature.

The sample preparations for the two developed methods were conducted the same way by the following method. The sample was fractured and sifted through sifter: with the netting of $02 \mathrm{~K}$ until complete passing, then through sifter with the netting of $018 \mathrm{~K}$; with the netting of $05 \mathrm{~K}$ until complete passing, then through sifter with netting of $045 \mathrm{~K}$; with the netting of $1 \mathrm{~K}$ until complete passing, then through sifter with the netting of $09 \mathrm{~K}$. The sample fractured completely because fractured parts of the sample affect the results of the research. The remaining fractures of the sample on sifters of $018 \mathrm{~K}$, $045 \mathrm{~K}$ and $09 \mathrm{~K}$ were washed from dust by distilled water and used in the researches. Dust-free fractures were transferred to the clean porcelain cup and dried out in the dryer at $105-115^{\circ} \mathrm{C}$ to the constant mass. Immediately after drying, these samples were made into samples of $2 \mathrm{~g}$, weighed with an error less than $0.001 \mathrm{~g}$.

The research method of corrosion activity of the humidity is based on the interaction between alkali and earth metals present in the amorphous phase of brick material and the water. This method is used to study the kinetics of the first stage of the degradation process of brick's material.

When preparing the aliquot, a brick material sample was placed in a $500 \mathrm{ml}$ conical flask adding $250 \mathrm{ml}$ of distilled water. The flask was kept for $0.5,1.5$ and 25 hours at $22^{\circ} \mathrm{C}$, $60^{\circ} \mathrm{C}$ and $100^{\circ} \mathrm{C}$. At the end of the study, the aliquot was presented for examination. The laboratory assessment parameters of the rate of alkali formation reactions when the brick material comes into contact with water are presented in Table 1 
Table 1. Parameters of the experiment during the contact of brick's material with water

\begin{tabular}{cccc}
\hline Fraction $\backslash$ Temperature & $\mathbf{2 2}^{\circ} \mathbf{C}$ & $\mathbf{6 0}^{\circ} \mathbf{C}$ & $\mathbf{1 0 0}^{\circ} \mathbf{C}$ \\
\hline \multirow{2}{*}{$0.18-0.20 \mathrm{~mm}$} & 1 hour; & 1 hour; & 0.5 hour; \\
& 5 hours; & 5 hours; & 1 hour; \\
& 25 hours & 25 hours & 5 hours \\
& 1 hour; & 1 hour; & 0.5 hour; \\
$0.45-0.50 \mathrm{~mm}$ & 5 hours; & 5 hours; & 1 hour; \\
& 25 hours & 25 hours & 5 hours \\
& 1 hour; & 1 hour; & 0.5 hour; \\
& 5 hours; & 5 hours; & 1 hour; \\
$0.9-1.0 \mathrm{~mm}$ & 25 hours & 25 hours & 5 hours \\
\hline
\end{tabular}

The concentration of the elements dissolved into water solution was determined by mass-spectrum with inductivelycoupled plasma and atomic-emission with inductivelycoupled plasma methods. The following equipment was used: inductively-coupled plasma mass spectrometer Elan-6100 ("Perkin Elmer", USA) and inductively-coupled plasma atomic-emission spectrometer Optima 4300 DV ("Perkin Elmer", USA). The research was conducted using the methods developed considering recommendations of the equipment manufacturer. Elements determined in the solution: $\mathrm{K}, \mathrm{Na}, \mathrm{Ca}$, $\mathrm{Mg}, \mathrm{Si}, \mathrm{Al}, \mathrm{S}, \mathrm{Fe}$.

The method used to determine the speed of the brick degradation is based on the interaction between alkali with the brick material and the multiple effects of alkali on the brick. The method also determines the change of sample mass before and after the effects and the time of this change. This method is intended for the research of kinetics of the second stage of chemical degradation.

The research was carried out in stages. A sample was put into a $500 \mathrm{ml}$ conical in each stage, where $250 \mathrm{ml}$ of potassium hydroxide solution were added. In the research, the solution with the concentrations of $0.05 \mathrm{~N}, 0.5 \mathrm{~N}$ and $5.0 \mathrm{~N}$ was used. The process of interaction between potassium hydroxide and brick's material was studied at temperatures of $22^{\circ} \mathrm{C}, 60^{\circ} \mathrm{C}$ and $100^{\circ} \mathrm{C}$. The time of interaction between brick's material and alkali solution was chosen with the dependence of temperature at which the research was conducted, and on each stage of the research, it was: one hour at a temperature of $100^{\circ} \mathrm{C}$, three hours at a temperature of $60^{\circ} \mathrm{C}$ and 10 days at a temperature of $22^{\circ} \mathrm{C}$. After each stage of the research, alkali solution was gently poured out; the sample was washed and dried out at $105-115^{\circ} \mathrm{C}$. The dried sample was immediately weighed on the balances with an error of less than $0.001 \mathrm{~g}$. The sample was put back into the flask after the weighing. The research was repeated until the masses of the sample in two subsequent tests were different by less than $0.01 \mathrm{~g}$, i.e. $0.5 \%$ from the initial mass of the sample.

Table 2. Parameters of the experiment during the contact of brick's material with potassium hydroxide

\begin{tabular}{cccc}
\hline Concentration\Fraction & $\begin{array}{c}\mathbf{0 . 1 8 - 0 . 2 0} \\
\mathbf{m m}\end{array}$ & $\begin{array}{c}\mathbf{0 . 4 5 - 0 . 5 0} \\
\mathbf{m m}\end{array}$ & $\begin{array}{c}\mathbf{0 . 9 - 1 . 0} \\
\mathbf{m m}\end{array}$ \\
\hline \multirow{3}{*}{$0.05 \mathrm{~N} \mathrm{KOH}$} & $22^{\circ} \mathrm{C} ;$ & $22^{\circ} \mathrm{C} ;$ & $22^{\circ} \mathrm{C} ;$ \\
& $60^{\circ} \mathrm{C} ;$ & $60^{\circ} \mathrm{C} ;$ & $60^{\circ} \mathrm{C} ;$ \\
& $100^{\circ} \mathrm{C}$ & $100^{\circ} \mathrm{C}$ & $100^{\circ} \mathrm{C}$ \\
$0.5 \mathrm{~N} \mathrm{KOH}$ & $22^{\circ} \mathrm{C} ;$ & $22^{\circ} \mathrm{C} ;$ & $22^{\circ} \mathrm{C} ;$ \\
& $60^{\circ} \mathrm{C} ;$ & $60^{\circ} \mathrm{C} ;$ & $60^{\circ} \mathrm{C} ;$ \\
& $100^{\circ} \mathrm{C}$ & $100^{\circ} \mathrm{C}$ & $100^{\circ} \mathrm{C}$ \\
& $22^{\circ} \mathrm{C} ;$ & $22^{\circ} \mathrm{C} ;$ & $22^{\circ} \mathrm{C} ;$ \\
$5.0 \mathrm{~N} \mathrm{KOH}$ & $60^{\circ} \mathrm{C} ;$ & $60^{\circ} \mathrm{C} ;$ & $60^{\circ} \mathrm{C} ;$ \\
& $100^{\circ} \mathrm{C}$ & $100^{\circ} \mathrm{C}$ & $100^{\circ} \mathrm{C}$ \\
\hline
\end{tabular}

The laboratory assessment parameters of the interaction rate of the brick material with potassium hydroxide are presented in Table 2 above.

For the description of the research results of brick's material by methods above, the following indicators were used:

Chemical resistance is the loss of sample mass during each stage of the interaction with chemical agents, $\mathrm{Cr}[\%]$.

Chemical resistance of ceramic material on each stage of the test, in per cent, is calculated by the following formula:

$$
C r=\frac{m-m_{1}}{m} 100,[\%]
$$

where, $m_{l}$ - sample's mass of ceramic material after the test, g; $m$ - initial sample's mass of ceramic material before the test, $\mathrm{g}$. Critical chemical resistance $\left(C r_{\max }\right)$ is the critical loss of sample mass during the experiment [\%]. Critical chemical resistance shows the amount of agent in the sample of brick material that is not destructed or destructed very slowly under the alkali effect.

Chemical destruction coefficient $(C d)$ is a portion of the sample, defined in per cent, destructed in the chemical effect process in time, defined in hours, [\%/hour]. The chemical destruction coefficient equals the ratio of chemical resistance of the material to the time when this value of chemical resistance of the material is achieved.

The chemical destruction coefficient is defined as follows. By obtaining the chemical resistance of ceramic material in each test, the graph of dependence of chemical resistance to time of effect on the material is made. The trend line of this graph is drawn from the interception point of coordinates. The points of the graph are included only if the utmost one has the value of chemical resistance that differs from the value of critical chemical resistance less than 3\%. The tangent of the slope of the graph to the horizontal axis (time) or the coefficient of the linear equation of the trend line equals the chemical destruction coefficient, defined in [\%/hour] and characterizes the speed of the chemical degradation process material.

\subsection{Calculations and mathematical model}

Degradation processes (formation of the alkalis from water and solid phase, and reactions of the alkalis with solid-phase) directly depend on temperature and ion concentrations of alkalis and earth-alkalis metals in the liquid phase. During the operation of the actual construction enclosure, it was affected by many factors that influence the temperature, humidification and, by implication, ions concentration. Humidity that moves through construction by the influence of vapour permeability and hydraulic conductivity enables degradation mechanisms described before. On the other hand, alternating temperature effects create different conditions for degradation processes in different layers when permeating the construction. Analysis of the heat and humidity distribution through construction is quite difficult in general. It is solved entirely only numerically, which is ineffective for the use of other complex processes, in this case - degradation. However, overviewing the general mechanism for the relatively easy cases allows understanding the transition principle of heat and humidity effects on the material degradation and concluding that it can be applied to complex constructions.

Humidity can permeate the construction in several ways as vapour from the rooms, rain, groundwaters, etc. For the singlelayered brick walls, all types of humidification can occur. 
Since corrosion speed is directly proportional to material humidification, the most humidified parts to degrade first are those affected by the corresponding temperatures. Since the corrosion limits the durability of the construction by the weakest parts, it is interesting to evaluate the corrosion speed for the entirely humidified part with the most conducive temperature mode for the corrosion. Finding these parts and the rate of the corrosion effect on the material, in general, appear like a complex problem that requires knowledge of the non-stationary distribution of temperature in the construction.

This article reviews the mechanism of heat transfer at nonstationary conditions for the single-layered brick wall. To simplify the analysis of the general process, the equation of heat transfer is used to find the simplified analytical solution that helps make necessary conclusions without significant errors. The obtained solution complements the developed mode of material's degradation of a wall and allows for quantitative assessments of degradation's speed.

In general, corrosion speed of the construction's material with the use of the results from 2.1 can be written as the function of temperature, alkalis concentration and humidity of the material (1):

$$
C d=C d_{0} \gamma_{1}^{\frac{t}{10}-10}\left(\frac{k}{k_{0}}\right)^{n} \frac{w}{w_{\max }}
$$

where $C d_{0}$ - dimension factor that equals corrosion speed of the material at maximum humidification of the material $w_{\max }$, alkalis concentration $k_{0}=0.5 \mathrm{~N}$ and temperature $100^{\circ} \mathrm{C} ; \gamma_{1}$ temperature coefficient of the speed.

So, corrosion speed is a function of the temperature and humidity of the material that is unevenly distributed over the construction depth in the operation process.

For the positive temperatures, with the use of the results of 2.1:

$$
\begin{aligned}
& C d=C d_{0} \gamma_{1} \frac{t}{10}-10\left(\frac{k_{p 22}}{k_{0}} \gamma_{2}^{\frac{t}{10}-2,2}\right)^{n} \frac{w}{w_{\max }} \\
& =C d_{0} \gamma_{1}{ }^{-7,8}\left(\frac{k_{p 22}}{k_{0}}\right)^{n}\left(\gamma_{1} \gamma_{2}{ }^{n}\right)^{\frac{t}{10}-2,2} \frac{w}{w_{\max }}
\end{aligned}
$$

where $\gamma_{2}$ - temperature coefficient for the maximum concentration; $\mathrm{k}_{\mathrm{p} 22}$ - maximum equilibrium concentration of the solution at $22^{\circ} \mathrm{C}$.

To find the most critical areas of the construction and their effective time, the assumption that these areas of the construction would be at maximum humidification would be used. Then, the approximate derived solution of the heat conduction equation allows evaluating the effect of operational conditions on the corrosion speed.

The shortened solution looks as following (3):

$$
\begin{aligned}
t(x, z)= & t_{\text {o.avg }}(z)+\frac{t_{i}-t_{\text {o.avg }}(z)}{R_{0} \alpha_{H}} \\
& +\frac{t_{i}-t_{\text {o.avg }}(z)}{R_{0}} \frac{x}{\lambda} \\
& +C_{e}^{-k \frac{x}{\delta} \sin \left(\omega z-k \frac{x}{\delta}+m\right)}
\end{aligned}
$$

where,

$x$ - coordinate of construction layer, measured from the outer end, m; $z$ - time, s;

$t_{i}$ - temperature of inner air, ${ }^{\circ} \mathrm{C}$;

$t_{\text {o.avg }}$ - the average temperature of outside air, ${ }^{\circ} \mathrm{C}$, can slowly change in time, for example, monthly average temperature;

$\alpha_{o}$ - heat transfer coefficient on the outer surface of the construction, $\mathrm{W} /\left(\mathrm{m}^{2 * \circ} \mathrm{C}\right)$;

$\delta$ - construction thickness, $\mathrm{m}$;

$R_{0}$ - conditional resistance of construction's heat transfer, $\mathrm{m}^{2 * \circ} \mathrm{C} / \mathrm{W}$

$\lambda$ - heat conduction of the material, $\mathrm{W} /\left(\mathrm{m}^{* \circ} \mathrm{C}\right)$;

$\omega$ - frequency of rapid temperature fluctuations of the outer air, $\mathrm{s}^{-1}$, daily in general.

Here, the first 3 terms of the formula represent the effect of average temperature in the yearly cycle. The changed pattern of average temperature is not crucial while it is relatively slow. The following parts are considered a sinusoid because their representation is the best for the cyclic change of the average temperature. For practical use, this temperature's cycle can be approximated by monthly average values. The last term of the formula represents the daily changes.

For the implementation of temperature's distribution to the corrosion speed of the construction material, it is convenient to use yearly material's corrosion. Since we are using cyclic repetitive climatic conditions and states of the construction, the yearly corrosion of the material would be the same for all years in the first approximation.

For the part of the construction where the operational temperature never falls under $-1^{\circ} \mathrm{C}$ (never freezes), yearly corrosion of the material looks as following (4):

$$
C d_{\text {year }}=\int_{0}^{z y e a r} C d d z
$$

With the use of the results from section 2.1 (5):

$$
\begin{aligned}
& C d_{\text {year }} \\
& =C d_{0} \gamma_{1}^{-7,8}\left(\frac{k_{p 22}}{k_{0}}\right)^{n} \int_{0}^{z_{\text {year }}}\left(\gamma_{1} \gamma_{2}{ }^{n}\right)^{\frac{t}{10}-2,2} \frac{w}{w_{0}} d z
\end{aligned}
$$

In the extreme case for the part with constant maximum humidification, formula (5) can be simplified further:

$$
C d_{\text {year }}=C d_{0} \gamma_{1}{ }^{-7,8}\left(\frac{k_{p 22}}{k_{0}}\right)^{n} \int_{0}^{z_{y e a r}}\left(\gamma_{1} \gamma_{2}{ }^{n}\right)^{\frac{t}{10}-2,2} d z
$$

Considering quantitative values of coefficients used in formula (6), it can be further simplified and written in the approximate form:

$$
\begin{aligned}
& C d_{\text {year }} \\
& \approx C d_{0} \gamma_{1}{ }^{-7.8}\left(\frac{k_{p 22}}{k_{0}}\right)^{n} \frac{\vartheta}{\ln \left(\gamma_{1} \gamma_{2}^{n}\right)}\left(\gamma_{1} \gamma_{2}^{n}\right)^{\frac{t_{\max }}{10}-2.2}
\end{aligned}
$$

where $\vartheta$ - coefficient of time, hour/year;

For the formula (7) $t_{\max }$ can be found by the simplified formula:

$$
t_{\text {max }}(x)=t_{\text {avg_jul }}+\frac{t_{i}-t_{\text {avg_jul }}}{R_{0}} \frac{x}{\lambda}+t_{\omega} e^{-k \frac{x}{\delta}}
$$

The limit of the zone where water never freezes can be approximately found with the formula: 


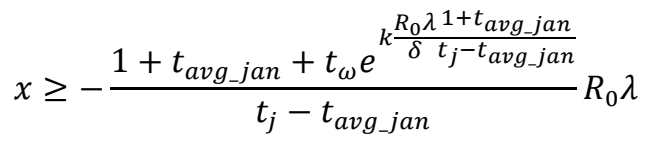

The exponential term in formula (9) can be discarded in the rough approximation since it is a minor correction for the other terms.

Group of formulas (7)-(9) allows to fully evaluate the maximum yearly corrosion of the construction's material in the non-freezing layers of the construction.

For the part of the construction that is affected by many freeze-thaw cycles, the limits of the zone would be: outer limit on the left and the minimum of two coordinates on the right:

$$
\begin{gathered}
x_{a}=-\frac{4+t_{\text {avg_jan }}+t_{\omega} e^{k \frac{R_{0} \lambda 4+t_{\text {avg_jan }}}{\delta t_{j}-t_{\text {avg_jan }}}} R_{0} \lambda}{t_{j}-t_{\text {avg_jan }}} \\
x_{b}=\frac{\delta}{k} \ln \left(\frac{t_{\omega}}{5}\right)
\end{gathered}
$$

When the extreme conditions are known, using formula (3), the duration of a period where the sought part is at positive temperatures, duration of a regular freeze-thaw period and duration of a period with completely frozen water where corrosion does not proceed. By the duration of a regular freeze-thaw period can be found the amount of freeze-thaw cycles that would be used in the yearly corrosion calculations.

For the case of construction humidification in limits of sorption humidity of the materials, the approximate method of calculation is used. For the single-layered constructions where the humidity of the material does not exceed the extreme sorption, the humidity distribution is directly related to the distribution of partial pressure of the water steam described by the equation similar to the heat conduction equation.

$$
\gamma_{0} \frac{\partial w}{\partial \varphi} \frac{1}{E} \frac{\partial e}{\partial z}=\mu \frac{\partial^{2} e}{\partial x^{2}}
$$

where,

$e$ - partial pressure of water vapour, $\mathrm{Pa}$;

$E$ - the pressure of saturated water vapour, $\mathrm{Pa}$, depends on temperature;

$\gamma_{0}$ - density of dry material, $\mathrm{kg} / \mathrm{m}^{3}$;

$\mu$ - calculated vapor permeability of the material, $\mathrm{kg} /(\mathrm{m} * \mathrm{~s} * \mathrm{~Pa})$;

$\frac{\partial w}{\partial \phi}$ - derivative of sorption isotherm, $\% / \%$.

The main difference between this equation and the heat conduction equation is the variable capacity of the material.

Sufficiently rough distribution of partial pressure of the water stream in the depth of a single-layered construction's enclosure can be found by analogue to temperature distribution as the sum of two functions slowly changing in yearly changes of temperature of humidity:

$$
U=e_{o . a v g}+\frac{e_{i}-e_{o . a v g}}{R_{p o} \beta_{0}}+\frac{e_{i}-e_{o . a v g}}{R_{p o}} \frac{\delta}{\mu} y
$$

And with rapid daily fluctuations:

$$
\begin{gathered}
V=\frac{\beta_{0} \frac{\delta}{\mu} e_{\omega}}{\sqrt{\left(k+\beta_{0} \frac{\delta}{\mu}\right)^{2}+k^{2}}} e^{-k y} \sin \left(v_{w} F_{0}-k y\right. \\
\left.-\frac{k}{k+\beta_{0} \frac{\delta}{\mu}}\right)
\end{gathered}
$$

$v_{w}$ is found by the formula:

$$
v_{w}=\omega \delta^{2} \frac{\gamma_{0} \frac{\partial w}{\partial \varphi}}{\mu E}
$$

Conducted analysis shows that in the most common brick walls with a depth of 1.5-2.5 bricks, solution (3) together with solution (13)-(15) describes the distribution of humidity with a high degree in the wall's depth for the yearly and daily changes. These changes are the most interesting when analyzing the degradation of the wall's material.

\section{RESULTS}

\subsection{Results of the laboratory research}

The material of a solid clay brick used in the research was made in Russia. It has the following characteristics: strength 18.1 MPa, density - $1780 \mathrm{~kg} / \mathrm{m} 3$, frost resistance - 50 cycles. The following parameters were determined during the research: the dependence of the chemical corrosion reaction speed on alkali concentration in the solution; alkalis formation reaction speed during the brick material interaction with water; temperature coefficients in the equations of Van't Hoff and Arrhenius for given reactions; energy activation values of chemical reactions included in the degradation process in the building ceramic material.

As an example, Figure 1 shows the results of the research of hydration speed of the alkalis and earth-alkalis elements of the metals at the temperature of $22^{\circ} \mathrm{C}$, dispersion of the sample $0.45-0.5 \mathrm{~mm}$. Similar graphs were obtained for the other conditions of the experiment.

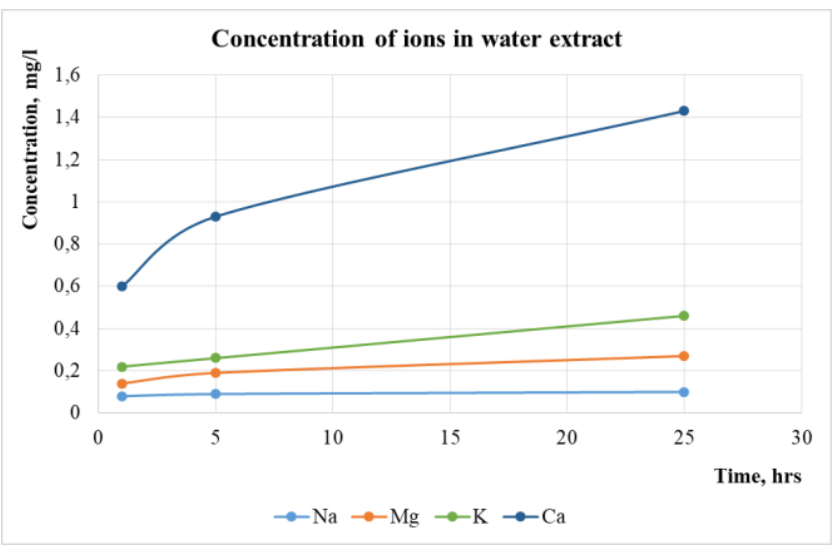

Figure 1. Results of the research of hydration speed of the alkalis and earth-alkalis metals during the temperature of $22^{\circ} \mathrm{C}$ 
Based on the experiment's results, equations of Van't Hoff for the hydration speed of the alkalis and earth-alkalis elements (16)-(19) were obtained and shown next:

$$
\begin{gathered}
C_{N a+}=C_{N a+} 22 * 1.43^{\frac{T-22}{10}}=9.250 * 1.43^{\frac{T-22}{10}} \\
C_{K+}=C_{K+^{22}} * 1.91^{\frac{T-22}{10}}=46.250 * 1.91^{\frac{T-22}{10}} \\
C_{M g 2+}=C_{M g 2+22} * 1.23^{\frac{T-22}{10}}=19.583 * 1.23^{\frac{T-22}{10}} \\
C_{C a 2+}=C_{C a 2+22} * 1.22^{\frac{T-22}{10}}=82.917 * 1.22^{\frac{T-22}{10}}
\end{gathered}
$$

The results of the conducted series of laboratory researches also allowed to determine the coefficient in the equation of Arrhenius. With the use of completed calculations, Arrhenius equations for the reactions of the interaction of alkalis and earth-alkalis elements of the brick's material with water are shown below:

$$
\begin{aligned}
& \text { For } \mathrm{Na}^{+}: \ln k=-\frac{928.615}{T}+5.373 \\
& \text { For } \mathrm{K}^{+}: \ln k=-\frac{1665.88}{T}+9.481 \\
& \text { For } \mathrm{Mg}^{2+}: \ln k=-\frac{543.479}{T}+4.81 \\
& \text { For } \mathrm{Ca}^{2+}: \ln k=-\frac{516.157}{T}+6.168
\end{aligned}
$$

Considering that activation energy of the reaction can be found from Eq. (24) and knowing Eqns. (20)-(23), it can be assumed that activation energy of the hydration reaction was found:

$$
E^{*}=-A R,
$$

where: $\mathrm{R}$ - universal gas constant, $\mathrm{R}=8.31 \mathrm{~J} /\left(\mathrm{mol}^{*} \mathrm{~K}\right)$;

A - numerator in the reverse temperature in Arrhenius equation.

It is important to note that the element concentration of alkalis and earth-alkalis metals in a water solution with a specific temperature and contact time has a maximum value, i.e. equilibrium value. This value of maximum concentration was determined for every element of the alkalis and earthmetals, and equations were made for the dependency of the equilibrium concentration of the elements on temperature. These values would be used for the mathematical model of the degradation process in part 2.2 of the paper.

Laboratory experiments of chemical resistance of the brick material were conducted at $22^{\circ} \mathrm{C}, 60^{\circ} \mathrm{C}$ and $100^{\circ} \mathrm{C}$; at three different concentrations of potassium hydroxide of $0.05 \mathrm{~N}, 0.5$ $\mathrm{N}$ and $5.0 \mathrm{~N}$ and with three contact areas of the brick material's sample with the fraction's sizes of $0.18-0.2 \mathrm{~mm}, 0.45-0.5 \mathrm{~mm}$ and 0.9-1.0 $\mathrm{mm}$.

As an example of experimental results, Figure 2 shows the results of laboratory experiments of the kinetic of the material degradation's process at the concentration of potassium hydroxide of $0.5 \mathrm{~N}$, brick's fractions of $0.45-0.5 \mathrm{~mm}$ and at temperatures of $100^{\circ} \mathrm{C}$ and $60^{\circ} \mathrm{C}$ and Figure 3 shows the same experiment at $22^{\circ} \mathrm{C}$. The three graphs show a similar destruction process depending on the time of the experiment The location of the graphs in different figures is since the destruction process of the brick material at $22^{\circ} \mathrm{C}$ flows much slower than at $60^{\circ} \mathrm{C}$ and $100^{\circ} \mathrm{C}$. The location of three graphs in one figure is not informative. The results of the experiment at $100^{\circ} \mathrm{C}$ and $60^{\circ} \mathrm{C}$ are shown conditionally in Figure 3.

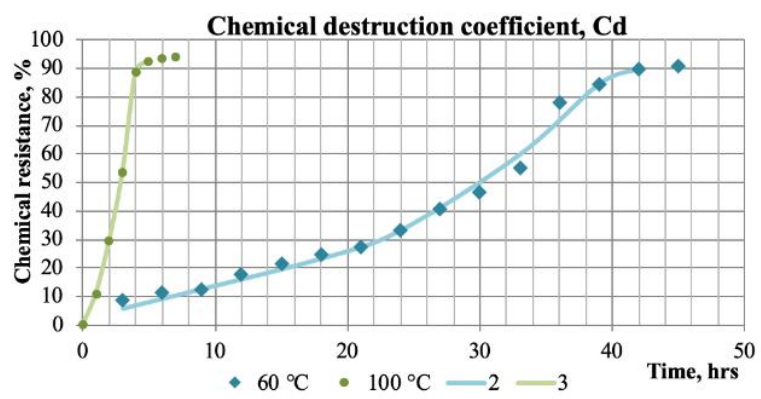

Figure 2. Degradation of the brick's material to time dependence of the process at $60^{\circ} \mathrm{C}$ and $100^{\circ} \mathrm{C}$

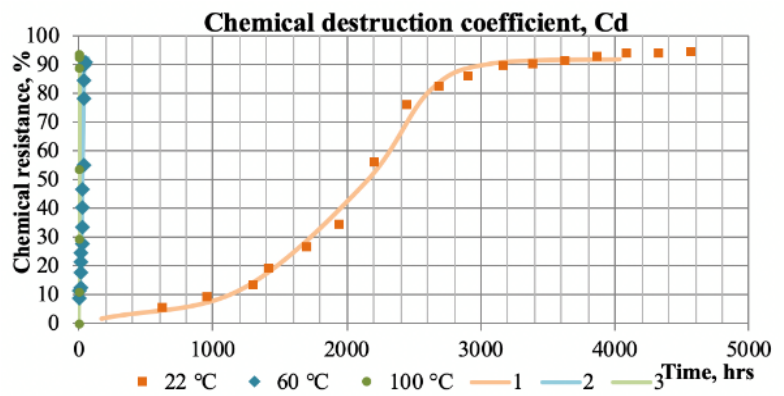

Figure 3. Degradation of the brick's material to time dependence of the process at $22^{\circ} \mathrm{C}$

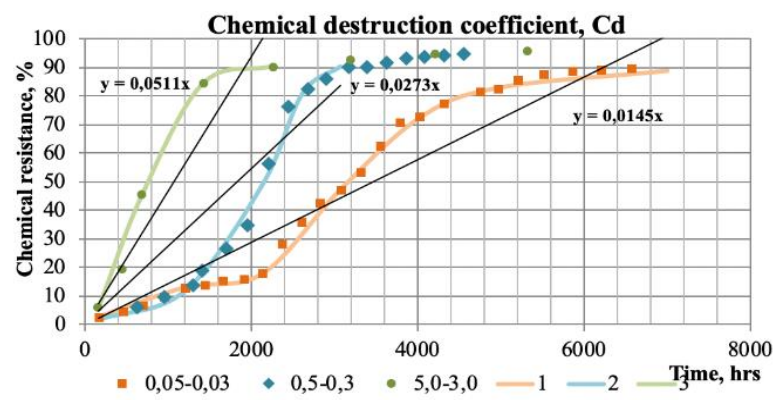

Figure 4. Graphical determination of the chemical degradation coefficient at $22^{\circ} \mathrm{C}$ and fraction size of $0.45-0.5$ $\mathrm{mm}$

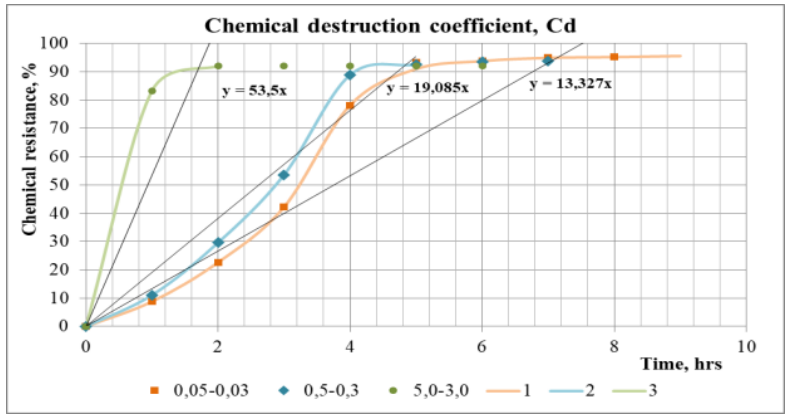

Figure 5. Graphical determination of the chemical degradation coefficient at $100^{\circ} \mathrm{C}$ and fraction size of $0.45-0.5$ $\mathrm{mm}$

The experiment results were analysis analyzed using a 
specifically developed method. In the result of the laboratory research analysis, the brick material's chemical degradation coefficient was found for different conditions of the process shown in Figures 4 and 5. Chemical degradation coefficient $C d$ was determined as a proportion of the sample, determined in per cent, that destructs in the process of chemical influence in time, determined in hours, $[\% / \mathrm{hr}]$. The chemical degradation coefficient equals the chemical resistance of the material divided by the time that passed until the given value of the chemical resistance was reached.

The results of the determination of chemical resistance of the ceramic material from each experiment are used to draw a graph with the dependency of chemical resistance to time of the influence on the material.

The trend line of the graph is drawn from the $(0 ; 0)$ point. Also, points of the graph are included only if the value of the chemical resistance differs by $3 \%$ from the critical chemical resistance. Plot slope tangent to the horizontal axis (time) or the linear equation coefficient of the trend line equals to chemical degradation coefficient of the material $(C d)$, has a $[\% /$ hour $]$ units and characterizes the speed of the chemical degradation process of the material.

The experiment results allowed determining the dependency of reaction speed on potassium hydroxide concentration and the process temperature. The chemical degradation coefficient should be used in the calculations. The equation describing the dependency of the speed of the brick material degradation on the concentration of alkalis is given below (25):

$$
\frac{k_{1}}{k_{2}}=\left(\frac{C d_{1}}{C d_{2}}\right)^{n}
$$

Then,

$$
n=\ln \frac{k_{1}}{k_{2}} / \ln \left(\frac{C d_{1}}{C d_{2}}\right)^{n}
$$

When comparing the experiment results for the concentrations $k_{0.5} / k_{0.05}$ and $k_{5} / k_{0.05}$, the power value of the power function (25) would be $\mathrm{n}=0.324$. This means that the dependency of reaction speed to alkali concentration would be following:

$$
\frac{k_{1}}{k_{2}}=\left(\frac{C d_{1}}{C d_{2}}\right)^{n}=\left(\frac{C d_{1}}{C d_{2}}\right)^{0.324}
$$

The temperature coefficient of the speed in Van't Hoff is the equation calculated using formula (28):

$$
k_{t}=\gamma^{n} * k_{t 0}
$$

Same as for hydration reactions, firstly, we are interested in processes in construction enclosures. It's rational to use the temperature coefficient of speed $\gamma$ that was found on the temperature intervals from $22^{\circ} \mathrm{C}$ to $60^{\circ} \mathrm{C}$. Then, the Van't Hoff equation for the degradation of brick material can be as follows:

$$
k_{t}=2.89^{n} * k_{t 0}
$$

where $n=\left(\mathrm{t}-\mathrm{t}_{0}\right) / 10$.

Arrhenius equation for the interaction's reaction of alkalis and earth-alkalis elements of the brick's material with water would be following:

$$
\ln k=-\frac{10403.15}{T+35.57}
$$

\subsection{Results obtained during method's probation}

For the analysis of obtained results, formulas (1) and (2) should be used for the calculations of the brick material durability in an actual construction enclosure.

In 2017, the author conducted field research on the Church of St. Nicholas Wet in Yaroslavl, Russia (Figure 6).

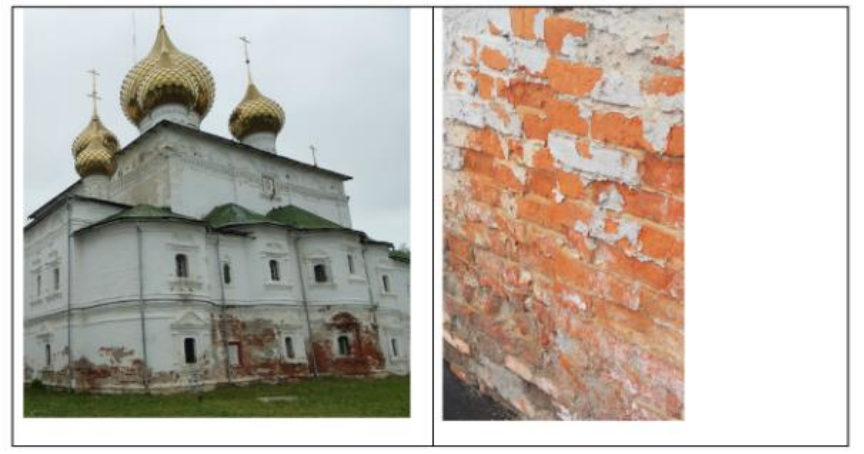

Figure 6. The state of brickwork construction's enclosure of Church of St. Nicholas Wet in Yaroslavl, Russia

In the field research, samples were obtained from the 3 parts of the construction enclosure: from the bottom row of brickwork (approx. $10 \mathrm{~cm}$ from the ground surface), the middle row of brickwork (approx. $120 \mathrm{~cm}$ from the ground surface) and from the second row of brickwork in the wall between the gallery and middle part of the church. Figure 6 clearly shows that the degradation of bricks in the bottom row is significantly higher than the degradation in the middle one.

Figure 7 shows obtained results of humidity distribution in the construction thickness. Humidification in the bottom row of the brickwork equals $8.1 \%$ to $11.4 \%$ mass, for the middle row $-0.7 \%$ to $1.8 \%$ mass. The calculated operational humidification of the brickwork is $w_{3}=9.91 \%$ in the bottom row and $w_{3}=0.99 \%$ in the middle row.

Let's take a look at calculations.

It can be assumed that alkalis concentration at positive temperatures equals maximum concentration.

$$
\begin{aligned}
C d=C d_{0} 2.89^{-7.8}\left(\frac{29.4 * 10^{-6}}{0.5}\right)^{0.324} \\
\\
\left.\quad * 2.23^{0.324}\right)^{\frac{t}{10}-2.2} \\
=C d_{0} 2.54 * 10^{-4} * 0.0426 \\
\\
*(3.75)^{\frac{t}{10}-2.2}
\end{aligned}
$$

At $20^{\circ} \mathrm{C}$ and critical humidification of the construction of $15 \%$ of the mass:

$$
\begin{gathered}
C d=22.5 * 2.54 * 10^{-4} * 0.0426 *(3.75)^{2-2.2} \\
=1.87 * 10^{-4}
\end{gathered}
$$

Considering formula (20) for the humidification of the construction of $9.91 \%$ and $0.99 \%$, the value $\mathrm{Cd}$ would be $1.24 * 10^{-4}$ and $0.12 * 10^{-4} \%$ /hour, respectively. 


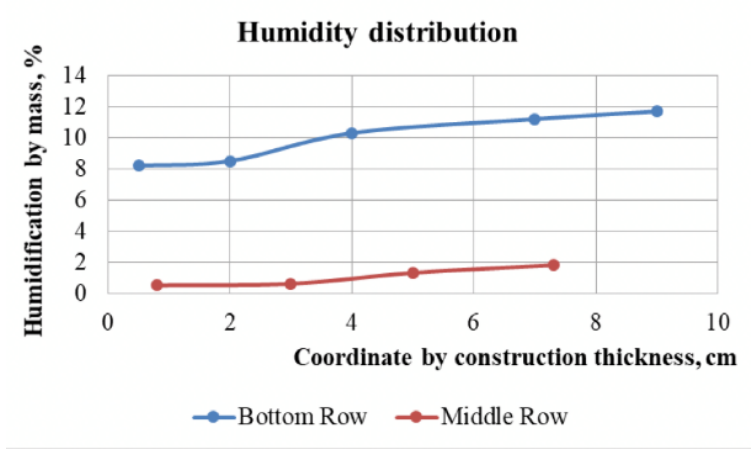

Figure 7. Humidity distribution in the brickwork construction's enclosure

Therefore, using bricks in heritage architecture, the brick material durability was 92 years at operational conditions of the bottom row and 925 years at operational conditions of the middle row. Considering that our calculations used characteristics of clay brick made in 2013 of M100 mark, obtained results are probable to evaluate the durability of the brick's material.

In the general case, all the calculations should use the calculation of humidification in the construction enclosure. It can be conducted numerically by specialized programs. However, using these programs is significantly more difficult than using programs for temperature field calculations, and it is uncommon in construction practice.

Analyze the Eq. (27) with the yearly changes in humidity and temperature because the inertia of humidification is significantly higher than the temperature's one.

For the wall made from solid bricks with a depth of 2 bricks $(\delta=0.51)$ :

$$
\frac{\partial w}{\partial \varphi}=0.03
$$

Sets by the last part of the sorption curve.

Density $1800 \mathrm{~kg} / \mathrm{m}^{3}$.

Vapor permeability $0.11 \mathrm{mg} /(\mathrm{m} * \mathrm{hr} * \mathrm{~Pa}), \quad 3.06 * 10^{-12}$ $\mathrm{kg} /(\mathrm{m} * \mathrm{~s} * \mathrm{~Pa})$.

$$
\begin{aligned}
v_{w}=\omega \delta^{2} \frac{1800}{3.06 *} & * 0.03 \\
& =10^{-12} E \\
& 1.98 * 10^{-7} \frac{0.51^{2}}{5.67 * 10^{-14} E} \\
& =\frac{9.1}{E} * 10^{5}
\end{aligned}
$$

Formula (31) shows that variable $v_{w}$ changes approximately from 300 to 2000 . Reviewing daily and even weekly changes makes no sense since they almost wholly appear in the outer layers of the construction.

For the single-layered construction made from polystyrene concrete with a depth of $400 \mathrm{~mm}$ :

$$
\frac{\partial w}{\partial \varphi}=0.13
$$

Density $400 \mathrm{~kg} / \mathrm{m}^{3}$.

Vapor permeability $0.023 \mathrm{mg} /(\mathrm{m} * \mathrm{hr} * \mathrm{~Pa}), \quad 6.39 * 10^{-12}$ $\mathrm{kg} /(\mathrm{m} * \mathrm{~s} * \mathrm{~Pa})$.

$$
\begin{aligned}
v_{w}=\omega \delta^{2} \frac{1}{0.123} & * 10^{-12} E \\
= & 1.98 * 10^{-7} \frac{0.4^{2}}{0.123 * 10^{-12} E} \\
= & \frac{2.576}{E} * 10^{5}
\end{aligned}
$$

Variable $v_{w}$ changes approximately from 100 to 750.

Therefore, Eq. (27) for the single-layered wall made from polystyrene concrete would be the same as for the brick wall. Daily fluctuations of climatic parameters are too rapid and can be ignored. Yearly fluctuations create the main effect on the construction.

Calculating the partial pressure of water vapour distribution by the thickness of a single-layered construction enclosure can be found using formulas (28)-(30).

\section{DISCUSSION}

In part I, it was noted that all mathematical models of material's degradation are based on the registration of external effects on the material with an aggressive environment or mechanical load [3, 4]. It uses difficult mathematical calculations that end up with the inability to implement the developed model $[11,12]$. Moreover, the error describing the main process of material degradation leads to distortion of the results of phenomenological models of degradation based on kinetic research of chemical processes [13].

This work reviews the processes of chemical degradation that take place inside the material without the effects of external chemical or mechanical loads. These conditions can be implemented to the model as additional factors that characterize operational conditions.

Parameters used in the mathematical model based on the results of the research of material itself, therefore developed method accounts for characteristics of the material itself - the speed of the alkali formation and the speed of alkali effect on the material itself - as well as external parameters temperature and humidity.

In the construction, different layers would be affected by different temperatures, constant and alternating. Formula (3) allows finding these layer's boundaries and determining their effect on the construction inside them.

Formula (1) implies that the rise of temperature accelerates the activity of chemical reactions and, therefore, the corrosions. But in the small range of negative temperatures in the water freeze process, the concentration of agents in the solution in the material's pores would rise very strongly (1000 times and higher at low initial values), leading to the acceleration of the corrosion process. The research of humidity crystallization process in the construction's enclosure, conducted by the authors, showing that the gradual freezing of the humidity with cooling of the material occurs at approximately $-1^{\circ} \mathrm{C}$ to $-7^{\circ} \mathrm{C}$ range. Frozen humidity thaws at heating temperatures of $1{ }^{\circ} \mathrm{C}$ to $2^{\circ} \mathrm{C}$.

Construction can be divided into the following parts:

1. Part where humidity never freezes;

2. Part where humidity freezes once a year;

3. Part where humidity has multiple freeze-thaw cycles.

The first and third parts are widely known, and they are often cited. However, they don't provide detailed instruments for their determination. The second part is usually not mentioned; however, its presence is clear from formula (2). 
Since the temperatures of relatively complete freezing and relatively complete thaw differ from each other approximately 6-8 degrees, yearly multiple freeze-thaw cycles require daily temperature changes of outside air to carry these changes to the construction depth. Formula (2) states that these changes exponentially decrease with the coordinate. Therefore, the depth would be reached where negative temperatures would exist at the corresponding monthly average temperatures, but the daily changes would not.

For example, for the wall, made of brickwork with a depth of $510 \mathrm{~mm}$ (standard construction for the central European part of Russia), this depth would be approximately $100 \mathrm{~mm}$ from the outer surface. Therefore, even in Moscow city (Russia), negative temperatures would exist after this line $(100 \mathrm{~mm})$ without mentioning more harsh climatic conditions, but there would be no freeze-thaw cycles. Each multi-layered construction differs and should be evaluated separately.

For the implementation of temperature's distribution to the corrosion speed of the material, it's convenient to use yearly corrosion of the material. Assuming that climatic and construction conditions are cyclic, the first approximation would have the same yearly corrosion of the material for all the years.

\section{CONCLUSIONS}

The main results of the presented work are the following:

1. A multi-stage process of structural ceramics chemical corrosion has been developed. The formation of alkalis from alkaline and earth metals oxides is supposed to occur in the brick material at the first chemical stage. The interaction of the alkalis formed in the brick material or/and entering it with a cement-sand solution, with silicon and aluminium oxides of the amorphous phase of the brick material occurs at the second chemical stage of the process. The non-chemical stage or the material wetting has been proved to be the limiting stage for the entire destruction process. The developed method considers the material characteristics (the rate of alkalis formation and the rate of action of alkalis on the material) and external parameters (temperature, humidity, and the design parameters of the enclosing structure).

2. Methods for laboratory research of the kinetics of the chemical destruction stages have been developed to determine the individual structural ceramics characteristics. These methods are studying the reaction rate during the formation of alkalis in the brick material, characterizing the first chemical stage of the process and determining the rate of destruction of the brick material under the action of alkalis in the second chemical stage of the destruction process.

3 . The approach to the structural ceramics adopted by the authors in which durability is considered a material property but not its ability to resist external factors allowed introducing a new performance indicator of structural ceramics, the coefficient of chemical destruction $\mathrm{Cd}$. The introduced indicator has a dimension of [\%/hour], which allows its use for calculating the material durability.

4. Combining the results of laboratory studies described in the form of empirical models with a phenomenological model built based on the fundamental physical chemistry laws will create a correct model of the material durability.

5. A mathematical model of the brick material destruction when used for the brickwork of the enclosing structure has been developed. The model describes the simultaneous destruction process of the material in the structure. This approach is available for porous materials with high vapour permeability, which fundamentally distinguishes it from mathematical models developed for dense materials and describes the process based on diffusion (Fick's law). An approximate solution of the heat equation is obtained. The equation allows describing the temperature distribution over the structure with great accuracy under annual and daily harmonic temperature fluctuations.

The resulting solution makes it possible to divide the structure into sections. The quality of the chemical corrosion process in each section is different. The influence of the nonstationary humidity regime of the enclosure structure on material corrosion has been shown. The basic formulas necessary for its accounting and analysis have been given. The temperature distribution proved to have the greatest qualitative influence on the ongoing process. At the same time, the humidity distribution changes its quantitative indicators.

6. The developed method has been applied for real objects. The test results prove the possibility of using this method not only as a scientifically based alternative to determining the material frost resistance durability but also as a basis for developing methods for automatic monitoring of the buildings upkeep control.

\section{ACKNOWLEDGMENT}

This research did not receive any specific grant from funding agencies in the public, commercial, or not-for-profit sectors. The authors declare there are no competing interests.

\section{REFERENCES}

[1] Fagerlund, G. (1977). The critical degree of saturation method of assessing the freeze/thaw resistance of concrete. Matériaux et Construction, 10: 217-229. https://doi.org/10.1007/BF02478693

[2] Fagerlund, G., Somerville, G., Tuutti, K. (1994). The residual service life of concrete exposed to the combined effect of frost attack and reinforcement corrosion. In: Proceedings of International Conference "Concrete across Borders" 1994. Danish Concrete Association, Lund University, 7071: 351-364.

[3] Mori, T., Koga, M., Hikosaka, Y., Nonaka, T., Mishina, F., Sakai, Y., Koizumi, J. (1991). Microbial corrosion of concrete sewer pipes, H2S production from sediments and determination of corrosion rate. Water Science and Technology, 23: https://doi.org/10.2166/wst.1991.0579

[4] Herb, S., Stair, J.O., Ringelberg, D.B., White, D.C., Flemming, H.C. (1995). Characterization of biofilms on corroded concrete surfaces in drinking water reservoirs. Water Science and Technology, 32: 141-147. https://doi.org/10.1016/0273-1223(96)00018-2

[5] Kaltwasser, H. (1976). Destruction of concrete by nitrification. European Journal of Applied Microbiology and Biotechnology, 3: 185-192. https://doi.org/10.1007/BF01385433

[6] Sand, W., Bock, E. (1991). Biodeterioration of mineral materials by microorganisms-biogenic sulfuric and nitric acid corrosion of concrete and natural stone. 
Geomicrobioliology Journal, 9: 129-138. https://doi.org/10.1080/01490459109385994

[7] Beijerinck, M.W. (1901). Uber oligonitrophile mikroben. Zentralbl Bakterol Parasitenkd Infektionskr Hyg Abt II, 7: 561-582.

[8] Colleran, E., Finnegan, S., Lens, P. (1995). Anaerobic treatment of sulphate-containing waste streams. Antonie van Leeuwenhoek, 67: 29-46. https://doi.org/10.1007/BF00872194

[9] Zagury, G.J., Kulnieks, V.I., Neculita, C.M. (2006). Characterization and reactivity assessment of organic substrates for sulphate-reducing bacteria in acid mine drainage treatment. Chemosphere, 64: 944-954. https://doi.org/10.1016/j.chemosphere.2006.01.001

[10] Hansen, T.A. (1994). Metabolism of sulfate-reducing prokaryotes. Antonie Van Leeuwenhoek, 66: 165-185. https://doi.org/10.1007/BF00871638

[11] Siemes, A., Vrouwenvelder, A., van den Beukel, A. (1985). Durability of buildings: a reliability analysis. Heron, 30: 3-48.

[12] Widdel, F., Hansen, T.A. (1992). The dissimilatory sulphate and sulphur-reducing bacteria. In: Balows, A., Trüper, H.G., Dworkin, M., Harder, W., Schleifer, K.-H. (eds) The prokaryotes, 2nd edn. Springer-Verlag, New York. pp. 583-624.

[13] Vincke, E., Boon, N., Verstraete, W. (2001). Analysis of the microbial communities on corroded concrete sewer pipes-A case study. Applied Microbiology and Biotechnology, 57: 776-785. https://doi.org/10.1007/s002530100826

[14] Fagerlund, G. (1977). The international cooperative test of the critical degree of saturation method of assessing the freeze/thaw resistance of concrete. Matériaux et Construction, 58: 231-253. https://doi.org/10.1007/BF02478694

[15] Litvan, G. (1988). The mechanism of frost action in concrete - Theory and practical implications. In: Proceedings of Workshop on Low Temperature Effects on Concrete. IRC/NRCC, Ottawa. pp. 116-27.

[16] Pashinskij, V.A., Sidej, V.N. (2015). Method of evaluating the durability of building ceramics by the criterion of frost resistance. In: New Ideas of the New Century: Materials of an International Scientific Conference. FAD TOGU.

[17] Sarja, A., Vesikari, E. (1996). Durability design of concrete structures. Report of Rilem Technical Committee 130-CSL. Taylor \& Francis, London and New York.

[18] Zheldakov, D.Y. (2020). The brick material durability in brickwork. AlfaBuild, 15: 1504. https://doi.org/10.34910/ALF.15.4

[19] Zheldakov, D.Y. (2020). Brickwork chemical corrosion features. IOP Conference Series: Earth and Environmental Science, 459: 062089. https://doi.org/10.1088/1755-1315/459/6/062089

[20] Aleksandrovskij, S.V. (2003). Durability of external enclosing structures. NIISF RAASN, Moscow.
[21] Avizienis, A., Laprie, J.C., Randell, B. (2001). Fundamental Concepts of Dependability, University of Newcastle upon Tyne, Computing Science. https://www.ppgia.pucpr.br/ alcides/Teaching/Sistemas Distribuidos/TOF/avizienis01fundamental.pdf, accessed on Jan. 13, 2021.

[22] Zheldakov, D.Y. (2019). Chemical corrosion of the brickwork. Construction Materials, 4: 36-43. https://doi.org/10.31659/0585-430X-2019-769-4-36-43

[23] Andrade, C., Alonso, M.C., Pettersson, K., Somerville, G., Tuutti, K. (1994). The practical assessment of damage due to corrosion. In: Proceedings of Int. Conf. Concrete across Borders 1994. Danish Concrete Association, Lund. pp. 337-50.

[24] Moskvin, V.M., Ivanov, F.M., Alekseev, S.N., Guzeev, E.A. (1980). Corrosion of Concrete and Reinforced Concrete. Methods of Their Protection, Strojizdat.

\section{NOMENCLATURE}

Cd chemical degradation coefficient

$\mathrm{Cr} \quad$ chemical resistance

$C r_{\max }$ critical chemical resistance

$m_{l} \quad$ sample's mass of ceramic material after the test, $g$

$m$ initial sample's mass of ceramic material before the test, $\mathrm{g}$

$C d_{0} \quad$ dimension factor

$w_{\max }$ maximum humidification of the material

$k_{p 22}$ maximum equilibrium concentration of the solution at $22^{\circ} \mathrm{C}$

$z \quad$ time, $\mathrm{s}$

$t_{i} \quad$ temperature of inner air, ${ }^{\circ} \mathrm{C}$

$t_{\text {o.avg }} \quad$ average temperature of outside air, ${ }^{\circ} \mathrm{C}$

$\alpha_{o} \quad$ heat transfer coefficient on outer surface of the construction, $\mathrm{W} /\left(\mathrm{m}^{2 * \circ} \mathrm{C}\right)$

$R_{0} \quad$ conditional resistance of construction's heat transfer, $\mathrm{m}^{2 * \circ} \mathrm{C} / \mathrm{W}$

$e \quad$ partial pressure of water vapor, $\mathrm{Pa}$

$E$ pressure of saturated water vapor, $\mathrm{Pa}$, depends on temperature

$\mathrm{R} \quad$ universal gas constant, $\mathrm{R}=8.31 \mathrm{~J} /\left(\mathrm{mol}^{*} \mathrm{~K}\right)$

A numerator in the reverse temperature in Arrhenius equation

\section{Greek symbols}

$\gamma_{1} \quad$ temperature coefficient of the speed

$\gamma_{2}$ temperature coefficient for the maximum concentration

$\delta \quad$ construction thickness, $\mathrm{m}$

$\lambda \quad$ heat conduction of the material, $\mathrm{W} /\left(\mathrm{m}^{*}{ }^{\circ} \mathrm{C}\right)$

$\omega$ frequency of rapid temperature fluctuations of outer air, $\mathrm{s}^{-1}$, daily in general

$\vartheta \quad$ coefficient of time, hour/year

$\gamma_{0}$ density of dry material, $\mathrm{kg} / \mathrm{m}^{3}$ 